\title{
Decomposition of Phenol in Water by Ozone Oxidation with Metal-Supported Carbongel
}

\author{
Noriaki SANO ${ }^{1,2}$, Takuji YAMAMOTO ${ }^{3}$, \\ Hiroki SHINOMIYA ${ }^{2}$, Akira ENDO ${ }^{3}$, \\ Apiluck EIAD-UA ${ }^{3}$, Apinan SoottitantaWAT ${ }^{4}$, \\ Tawatchai CHARINPANITKUL ${ }^{4}$, \\ Wiwut TANTHAPANICHAKOON ${ }^{5}$, Takao OHMORI ${ }^{3}$ \\ and Hajime TAMON ${ }^{1}$ \\ ${ }^{1}$ Department of Chemical Engineering, Kyoto University, Kyoto- \\ Daigaku Katsura, Nishikyo-ku, Kyoto-shi, Kyoto 615-8510, Japan \\ ${ }^{2}$ Department of Mechanical and System Engineering, University of \\ Hyogo, 2167, Shosha, Himeji-shi, Hyogo 671-2201, Japan \\ ${ }^{3}$ National Institute of Advanced Industrial Science and Technology, \\ Central 5, 1-1-1, Higashi, Tsukuba-shi, Ibaraki 305-8565, Japan \\ ${ }^{4}$ Center of Excellence in Particle Technology, Department of Chemical \\ Engineering, Chulalongkorn University, Patumwan, Bangkok 10330 \\ Thailand \\ ${ }^{5}$ National Nanotechnology Center, National Science and Technology \\ Development Agency Klong Luang, Pathumthani 12120, Thailand
}

Keywords: Phenol Decomposition, Ozone Oxidation, Carbongel

\begin{abstract}
Porous carbongel beads supporting $\mathrm{Co}$ or $\mathrm{Ni}$ were prepared to enhance decomposition of phenol in water with ozone oxidation. The carbongel beads were synthesized by carbonization of resorcinol-formaldehyde (RF) gel beads whose diameter was approximately $1 \mathrm{~mm}$. Co and $\mathrm{Ni}$ were supported on carbongel beads by impregnation with soluble nitrate salts of $\mathrm{Co}$ and $\mathrm{Ni}$ followed by thermal decomposition and post-oxidation treatment. In the experiments to decompose phenol, the enhancement effects of the carbongels supporting Co or $\mathrm{Ni}$ were observed, in which the degradation rate of phenol with these gels were larger than that with pristine carbongel or without any carbongel. In comparison between $\mathrm{Co}$ and $\mathrm{Ni}$, Co showed larger enhancement effect. In these experiments, the concentration of the residual ozone in water was monitored. It was revealed that the residual ozone is significantly reduced when Co was used. In the experiments with varied temperature $5,15,25^{\circ} \mathrm{C}$, the phenol degradation rate became the highest when the temperature was $5^{\circ} \mathrm{C}$, while the higher temperature of $25^{\circ} \mathrm{C}$ was preferable when a reduced concentration of residual ozone is demanded.
\end{abstract}

\section{Introduction}

The development of the methods to degrade organic compounds in water by oxidation has been important issue because toxic compounds which harm our health with extremely low concentration have been known to be serious threat. Dioxins and endocrine disruptors are well-known examples for such compounds. To develop advanced oxidation processes, some methods have been known to be effective. For instance, the methods using ozone, hydrogen peroxide, UV light, photocatalyst, ultrasounds, and combination of these effects have been reported (Kang and Hoffmann, 1998; Beltrán et al., 2003, 2005; Hsing et al., 2006).

Recently, water purification using the reactivity of

Received on July 1, 2008; accepted on October 6, 2008. Correspondence concerning this article should be addressed to N. Sano (E-mail address: sano@cheme.kyoto-u.ac.jp).

Presented at ISCRE 20 in Kyoto, September, 2008. ozone with organic compounds is attracting hot attention due to its efficiency and safety, which can be effective without toxic additives such as chloric oxidant. It has been reported that combination of solid catalyst with ozone can enhance the decomposition of organic compounds (Ernst et al., 2004; Fujita et al., 2004). Porous carbon (Yamamoto et al., 2002) can be one of the promising candidates for such catalyst because it possesses large surface area and appropriate pore size for diffusion-based processes. Among them, carbongel beads can be expected to be suitable materials as they can have well-controlled mesopores and the size of the pore is considered as preferable for catalytic reaction due to high diffusivity of reactants there. This expectation has been motivating us to develop water purification method with carbongel. In this study, we investigated the phenol degradation characteristics in ozonated water using carbongel beads supporting $\mathrm{Ni}$ or Co. Here, we observed not only the reaction rate of the degradation process but also the concentration of 
Table 1 Physical properties of porous beads used as catalyst support in this study $\left(S_{\mathrm{BET}}, V_{\mathrm{mes}}\right.$, and $V_{\text {mic }}$ correspond to specific surface area, mesopore volume and micropore volume, respectively)

\begin{tabular}{lcll}
\hline Sample & $\begin{array}{l}S_{\text {BET }} \\
{\left[\mathrm{m}^{2} \mathrm{~g}^{-1}\right]}\end{array}$ & $\begin{array}{l}V_{\text {mes }} \\
{\left[\mathrm{cm}^{3} \mathrm{~g}^{-1}\right]}\end{array}$ & $\begin{array}{l}V_{\text {mic }} \\
{\left[\mathrm{cm}^{3} \mathrm{~g}^{-1}\right]}\end{array}$ \\
\hline RFC-Ni & 669 & 1.21 & 0.16 \\
RFC-Co & 675 & 0.88 & 0.17 \\
AC-Ni & 1244 & 0.05 & 0.52 \\
AC-Co & 1314 & 0.08 & 0.56 \\
RFC & 672 & 0.76 & 0.17 \\
\hline
\end{tabular}

residual ozone concentration.

\section{Experimental}

\subsection{Synthesis of carbongel beads (RFC beads)}

Initially, a resorcinol-formaldehyde (RF) solution was prepared in the same manner as in a previous report (Yamamoto et al., 2002). Sodium carbonate was used as a basic catalyst for the sol-gel polycondensation with water as the diluent. The molar ratio of resorcinol to formaldehyde and the ratio of resorcinol to water were, respectively fixed at $0.5 \mathrm{~mol} \mathrm{~mol}^{-1}$ and 0.25 $\mathrm{g} \mathrm{cm}^{-3}$, respectively, while the molar ratio of resorcinol to sodium carbonate was fixed to $400 \mathrm{~mol} \mathrm{~mol}^{-1}$. The prepared RF solution was kept at $298 \mathrm{~K}$ for $24 \mathrm{~h}$ to effect the sol-gel polycondensation. Although colloidal sol particles were formed in the RF solution after this reaction time, the gelation remained incomplete. From this precursor, spherical gel beads whose diameter was approximately $1 \mathrm{~mm}$ were formed by a method using pulsed injection into a pumping tube. The spherical gel beads were washed with cyclohexane and ethanol, respectively, and then immersed in $t$-butanol to exchange the solvent in the pores before freeze-drying. The beads were dried at 253 $\mathrm{K}$ under a reduced pressure and carbonized at $1273 \mathrm{~K}$ in inert atmosphere. The porous properties of the beads were measured by nitrogen-gas adsorption experiments at $77 \mathrm{~K}$. Mesoporosity was determined according to the IUPAC definition (mesopore: $2 \mathrm{~nm}<$ pore diameter < $50 \mathrm{~nm}$ ). The pore-size distribution and mesopore volume were determined by applying the Dollimore-Heal method to the desorption isotherms. These properties are shown in Table 1. This table also shows the properties of activated carbon (AC) beads used for comparison in this study.

\subsection{Catalyst preparation}

First, carbongel beads (RFC beads) were immersed in an aqueous solution of $\mathrm{Ni}\left(\mathrm{NO}_{3}\right)_{2}$ or $\mathrm{Co}\left(\mathrm{NO}_{3}\right)_{2}$ and were subsequently dried at $60^{\circ} \mathrm{C}$ under reduced pressure. The RFC beads were then heated at $500^{\circ} \mathrm{C}$ under a $\mathrm{N}_{2}$ gas flow to decompose the metal nitrate. Finally, the im-

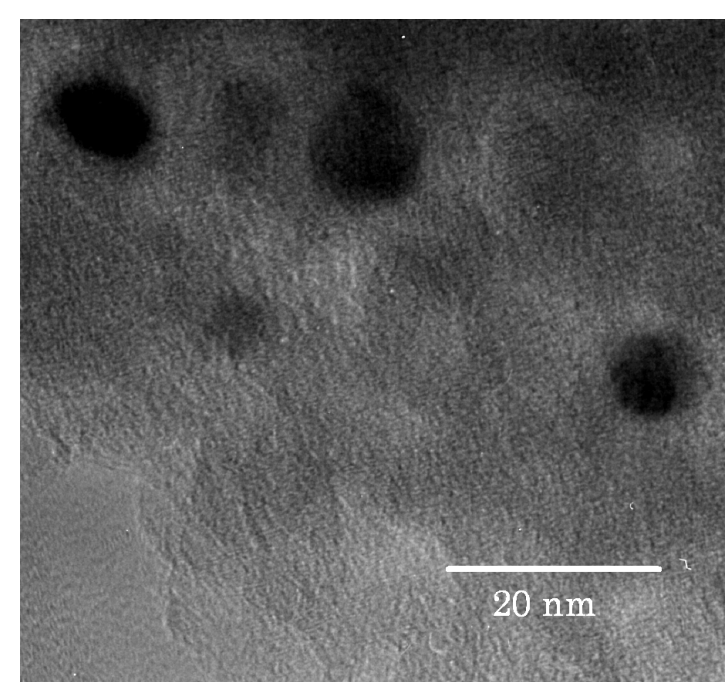

Fig. 1 TEM image of Ni-supported carbongel (RFC-Ni). The dark spots correspond to Ni particles

pregnated metal was oxidized in air at $200^{\circ} \mathrm{C}$. The loading ratio of metal was $5 \mathrm{wt} \%$. Figure 1 shows a typical TEM image of Ni-supported carbongel beads as example of metal-supported carbongel beads. It is shown that $\mathrm{Ni}$ particles whose diameters are approximately $5-15 \mathrm{~nm}$ are well dispersed.

\subsection{Degradation of phenol in water}

Figure 2 shows the apparatus used in the experiment to decompose phenol. The decomposition is based on ozone oxidation with metal-supported carbongel beads. To avoid surface destruction of the beads, we used a packed bed column to install the catalyst beads instead of a fluidized column. The target water was circulated by a Teflon-made pump at a flow rate $1.5 \mathrm{~L} / \mathrm{min}$ through a glass reservoir tank (inner diameter $=120 \mathrm{~mm}$, height $=$ $230 \mathrm{~mm}$ ) and a packed-bed column. The volume of the water circulated was $2 \mathrm{~L}$. The water circulation line consisted of glass tubes. The carbon gel beads $(1 \mathrm{~g})$ were packed in a glass column (inner diameter $=20 \mathrm{~mm}$ ). Ozone was generated by a discharge-based ozonizer (SO03UN-OX, Tokyu Car Corp.) at concentration $45 \mathrm{~g} / \mathrm{m}^{3}$, and was supplied to the target water at the reservoir tank by bubbling. The gas flow rate to supply ozone into water was $0.3 \mathrm{~L} / \mathrm{min}$. The dispersing filter for bubbling was made from glass particles and the pore size of this filter was $100-120 \mu \mathrm{m}$. The filter was placed about $8 \mathrm{~cm}$ below the water surface. Ozone concentration was monitored continuously by ozone meters with polarographic membrane (OZ-20, OZ-30, DKK-TOA). The initial concentration of phenol was adjusted to be $50 \mathrm{mg} \mathrm{L}^{-1}$ in distilled water. The initial value of $\mathrm{pH}$ in the targeted water was 3.2. We did not monitor $\mathrm{pH}$ during degradation process in this study although it is considered that $\mathrm{pH}$ may influence on the phenol degradation rate. The phenol concentration and byproduct formation was analyzed by a high performance liquid chromatograph with a photodi- 


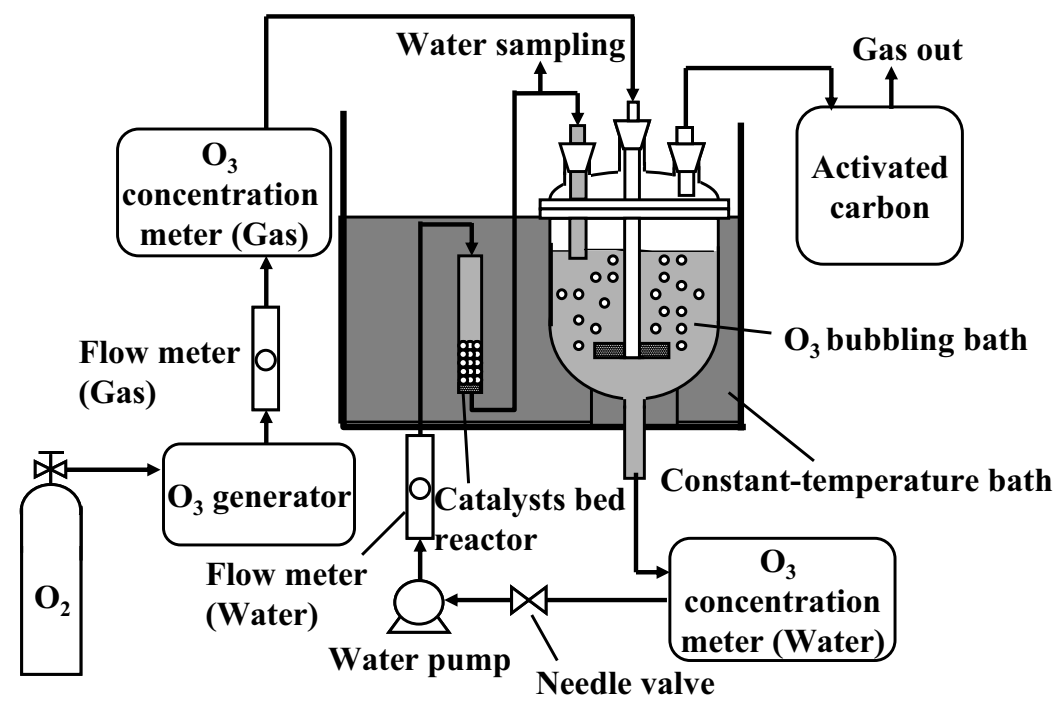

Fig. 2 Apparatus to decompose phenol in water using ozone and catalyst beads

ode array detector (HPLC) (SPD-20A, Shimadzu Corp.) and a gas chromatograph mass spectrometer (GCMS) (Clarus500GC/MS, Perkin Elmer). It was expected that phenol would adsorb on the surface of the catalyst beads used in this study. To evaluate such effect, the decrease of phenol concentration by adsorption on each bead without ozone was in advance measured. As a result, the all catalyst beads used in this study showed similar trends, in which the phenol concentration decreased to approximately $25 \mathrm{mg} \mathrm{L}^{-1}$ within $60 \mathrm{~min}$. This decreasing rate was significantly slower than that with ozone with the beads which had catalytic decomposition effect.

\section{Results and Discussion}

\subsection{Effect of catalyst beads on the phenol decompo- sition process}

Figure 3 shows the change of phenol concentration by ozone oxidation with the catalyst beads explained above. In this figure, the change of the phenol concentration without the catalyst beads is also shown for comparison. It is shown that phenol concentration can be decreased by ozone oxidation, and this concentration becomes almost zero in the investigated time range. It should be noticed that the use of catalyst beads can accelerate the decomposition of phenol. Although the decomposition rate of phenol using Ni-supported RFC beads is relatively lower compared with that using other beads, the decomposition rate with these beads seems to be approximately two times higher compared with the case of ozone only. Figure 4 shows the change of TOC concentration by ozone oxidation with the catalyst beads. Here also the result obtained in the case without catalyst beads is plotted for comparison. In this figure, the role of the catalytic metals is clearly shown. The decreasing rate of TOC concentration without catalyst beads $\left(\mathrm{O}_{3}\right.$ only) is signif-

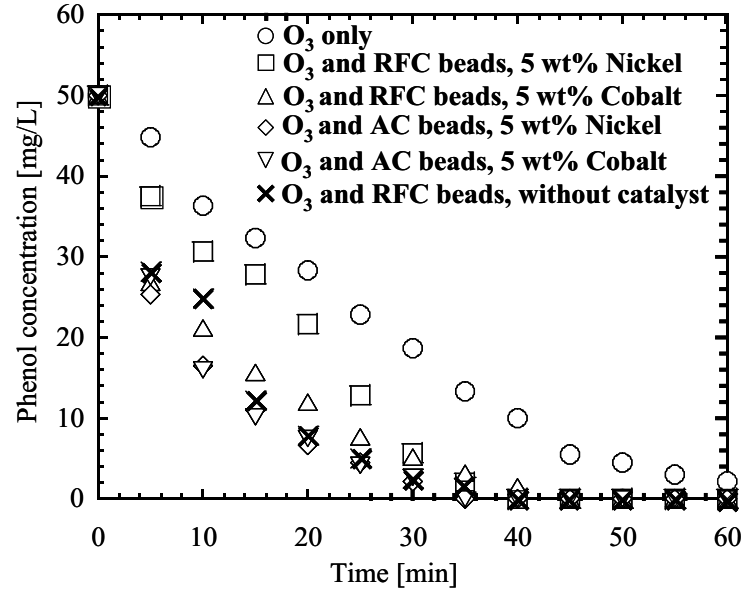

Fig. 3 The change of phenol concentration in the treated water by ozone oxidation with catalyst beads. Water temperature $=15^{\circ} \mathrm{C}$

icantly lower than that with catalyst beads. For the TOC change, the catalyst beads supporting $\mathrm{Ni}$ or Co showed clearly higher degradation rate than without metal supporting. In comparison between $\mathrm{Ni}$ and $\mathrm{Co}$, Co showed the enhancing effect on the TOC degradation more significantly. Among the catalyst beads used in this study, carbongel beads supported with Co showed the highest decomposition rate of TOC.

In the analyses by HPLC and GCMS, pyrocatechol, hydroquinone, and resorcinol were detected as byproducts. However, it should be noted that there are more byproducts which were not detected by these analyses. Pyrocatechol, hydroquinone, and resorcinol appeared in relatively early time range when the phenol concentration was decreasing with remaining TOC. Referring from other reported oxidation treatment of phenol which 


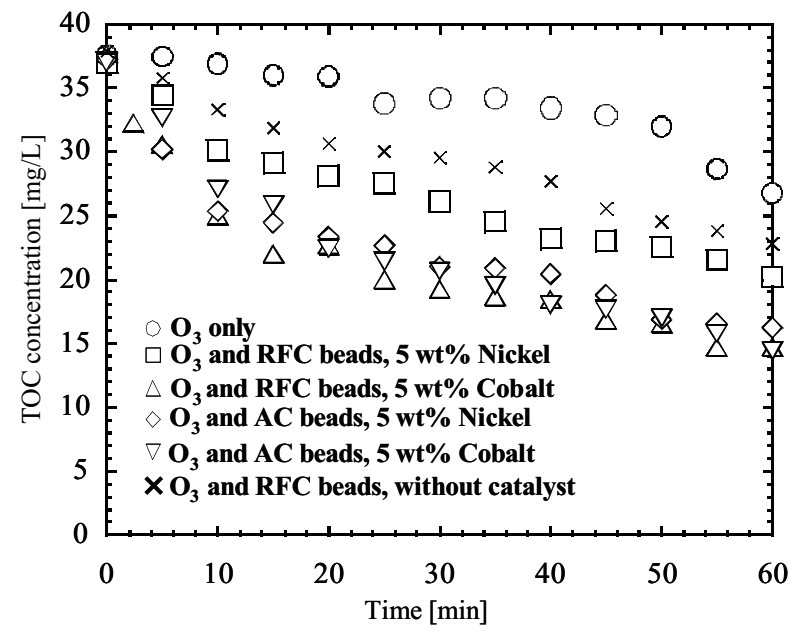

Fig. 4 The change of TOC concentration in phenol degradation treatment by ozone oxidation with catalyst beads. Water temperature $=15^{\circ} \mathrm{C}$

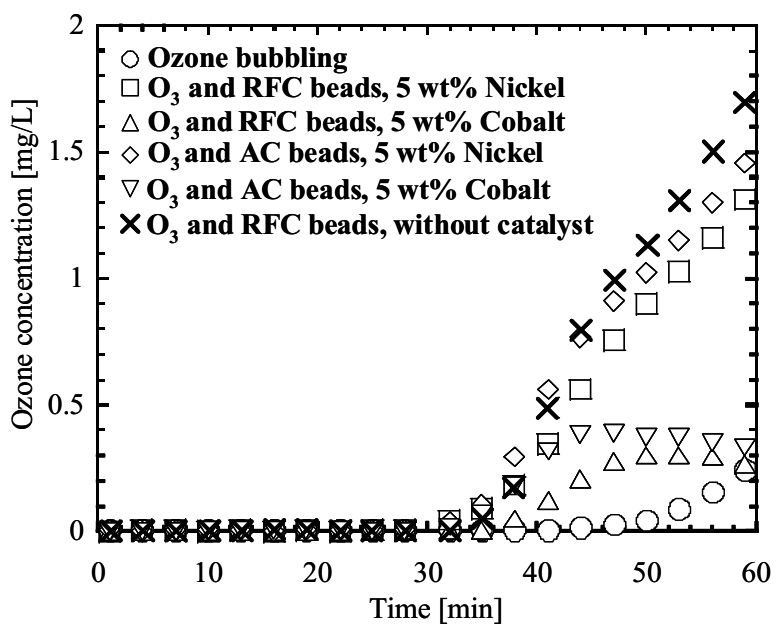

Fig. 5 The change of the concentration of aqueous ozone in phenol degradation treatment by ozone oxidation with catalyst beads. Water temperature $=15^{\circ} \mathrm{C}$

showed analogical trends of the byproduct formation (Sano and Yamamoto, 2005), the remaining TOC may contain relatively stable compounds, such as acetic acid. As ozone is obviously reactive with phenol and the conversion of phenol to byproducts is much faster than the decomposition of these stable byproducts, the phenol conversion can be enhanced easily than the TOC degradation. Thus, the phenol conversion could be enhanced by RFC beads which did not support metallic catalyst. However, it should be noticed that the degradation of TOC with decomposition of stable byproducts is more difficult than conversion of phenol. Therefore, the porous carbon beads supporting metallic catalysts can exhibit the contrasted effect to decrease TOC depending on catalyst species.

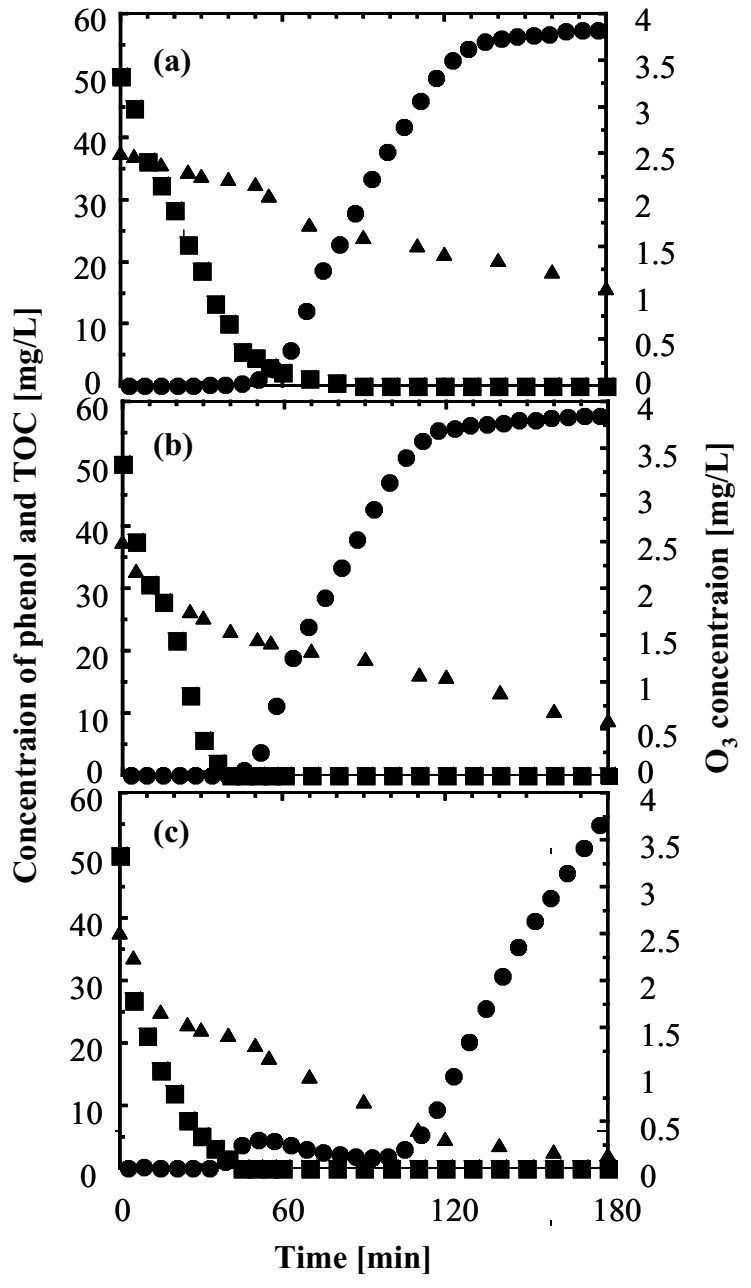

Fig. 6 Concentrations of phenol, TOC and aqueous ozone in the treated water in the degradation of phenol by ozone oxidation with (a) carbongel beads without metal support, (b) carbongel with $\mathrm{Ni}$ support, and (c) carbongel with Co support. Square, triangle, and circle correspond to the concentration of phenol, TOC, and ozone concentration in water, respectively. Symbols in figure, square, triangle, and circle correspond to phenol concentration, TOC concentration, and residual ozone concentration, respectively. Water temperature $=15^{\circ} \mathrm{C}$

Figure 5 shows the residual ozone concentration in water. In the all cases, the ozone concentration there started increasing when the phenol concentration became close to zero. Here, the catalyst beads with Co exhibits distinct feature. Except the beads with Co, the concentration of the residual ozone simply increased. On the contrary, the ozone concentration in water with Cosupported beads was limited, and it started decreasing after the ozone concentration became maximal. Especially, the Co-supported RFC beads showed the lowest residual ozone concentration.

Figure 6 shows the change of the concentration of phenol, TOC, and the residual ozone in water when the 


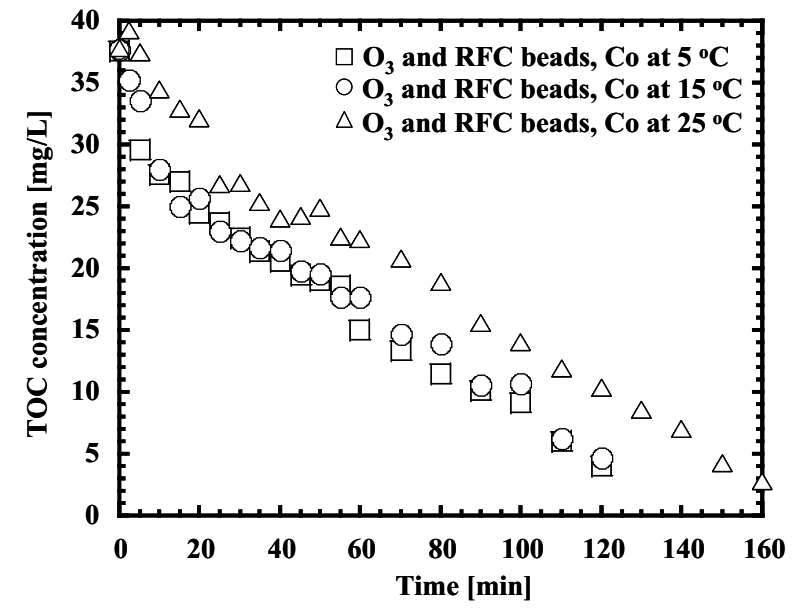

Fig. 7 The change of TOC concentration in the decomposition of phenol by ozone oxidation together with $\mathrm{Co}$ supported carbongel beads (RFC-Co) under varied temperature

decomposition of phenol was conducted with only ozone oxidation, and with ozone oxidation enhanced by $\mathrm{Ni}$ supported RFC beads or by Co-supported RFC beads. Here, results from AC beads were not shown because RFC-based catalysts showed similar tendency to the ACbased catalysts and they exhibited higher TOC degradation rate and lower residual ozone concentration than AC-based ones. In this figure, the concentration change is shown for a long time range so that the timing in the changes of the three concentrations are clearly depicted. Remarkable features in the decomposition of phenol with Co-supported RFC beads can be observed as follows; (1) The decrease of TOC concentration is faster than the other conditions. (2) The residual ozone concentration is significantly reduced in the time range since the phenol concentration becomes close to zero until the TOC concentration becomes approximately $7 \mathrm{mg} \mathrm{L}^{-1}$. In the case with other catalyst beads, the residual ozone concentration simply increases after the phenol concentration becomes close to zero and this concentration reaches the saturated value.

The mechanism of the effect of Co to reduce the concentration of the residual ozone concentration has not yet been clarified. To cause such effect, reaction path should be changed by using Co. This effect is not achieved by Ni. To elucidate this mechanism, detailed analysis of byproducts in the phenol degradation process especially in the time range when the residual ozone concentration is reduced (50-100 min in Figure 6(c)) will be necessary. The effect of Co to reduce the residual ozone is preferable for industrial application because the residual ozone must be removed before the treated water is released.

2.2 Influence of the temperature on the phenol decomposition with RFC beads

Figure 7 shows the change of TOC concentration with RFC beads with varied temperature 5,15 and $25^{\circ} \mathrm{C}$.

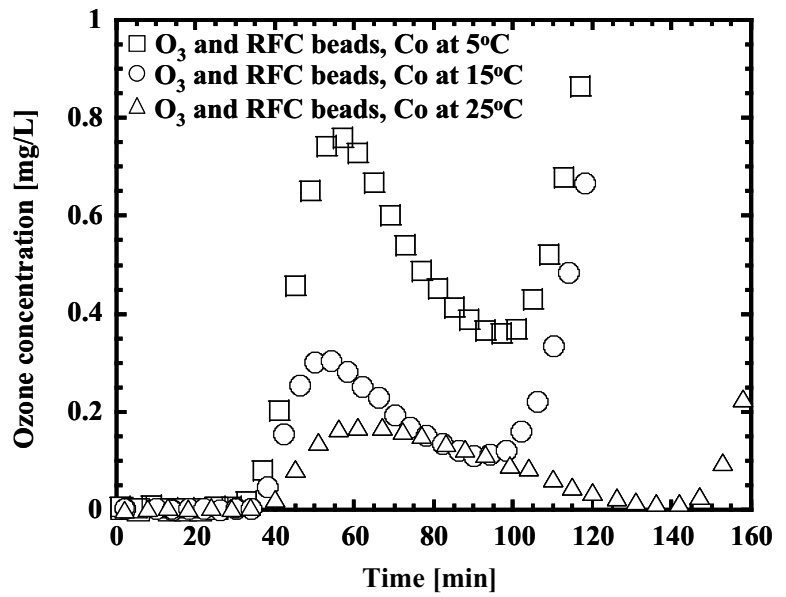

Fig. 8 The change of residual ozone concentration in water in the phenol decomposition process by ozone oxidation together with RFC-Co under varied temperature

It was found that the TOC decreasing rate tended to be higher with the lower temperature, and this rate with $25^{\circ} \mathrm{C}$ was clearly lower than that with 5 and $15^{\circ} \mathrm{C}$.

It should be noted that the decomposition rate of target compound by ozone oxidation is determined by the reactivity of ozone and its concentration. When the temperature is higher, normally the reactivity of ozone oxidation is higher according to Arrhenius-type expression (Beltran-Heredia et al., 2001). However, it can be expected that the residual ozone concentration in water should decrease when the temperature is higher because the solubility of ozone tends to be lower. To compare the solubility of ozone in water relatively, Henry constant is reported as $2820,3150,4530 \mathrm{~atm}^{-1}$ at 5,15 and $25^{\circ} \mathrm{C}$, respectively (Sugimitsu, 1996). This is the reason why the phenol degradation rate shown in Figure 7 decrease with the temperature.

Figure 8 shows the concentration of the residual ozone in water with the varied temperature, 5, 15 and $25^{\circ} \mathrm{C}$. It is shown that Co can reduce the residual ozone at all temperatures employed here. It is also observed that the concentration of the residual ozone became higher when the temperature was lower. This trend can be explained by the solubility of ozone into water as explained above, and the high ozone concentration causes the relatively high phenol treatment rate as shown in Figure 7. When the reduced ozone concentration in water is preferable, relatively high temperature such as $25^{\circ} \mathrm{C}$ is recommended for operational condition.

\section{Conclusions}

The carbongel beads supported with $\mathrm{Ni}$ or $\mathrm{Co}$ can promote ozone oxidation to degrade phenol in water. Compared with $\mathrm{Ni}$, Co can exhibit this effect more significantly. In addition, the effect of Co to reduce the concentration of the residual ozone in water was revealed. In 
the phenol degradation experiment with varied temperature, it is found that the phenol decomposition rate is higher when the temperature is lower because solubility of ozone is significantly higher with lower temperature. Nevertheless, in case when the reduced concentration of the residual ozone is preferable for exhaustion stage of the treated water, $25^{\circ} \mathrm{C}$ can be recommended in the temperature range $5-25^{\circ} \mathrm{C}$.

\section{Acknowledgments}

The financial support by NEDO is acknowledged. AS and TC gratefully acknowledge partial support from the centennial fund of Chulalongkorn University.

\section{Literature Cited}

Beltran-Heredia, J., J. Torregrosa, J. R. Dominguez and J. A. Reres; "Kinetics of the Reaction between Ozone and Phenolic Acids Present in Agro-Industrial Wastewaters," Water Res., 35, 10771085 (2001)

Beltrán, F. J., F. J. Rivas and R. Montero-de-Espinosa; "Mineralization Improvement of Phenol Aqueous Solutions through Heterogeneous Catalytic Ozonation," J. Chem. Technol. Biotechnol., 78, 1225-1233 (2003)

Beltrán, F. J., F. J. Rivas, O. Gimeno and M. Carbajo; "Photocatalytic
Enhanced Oxidation of Fluorene in Water with Ozone. Comparison with Other Chemical Oxidation Methods," Ind. Eng. Chem. Res., 44, 3419-3425 (2005)

Ernst, M., F. Lurot and J.-C. Schrotter; "Catalytic Ozonation of Refractory Organic Model Compounds in Aqueous Solution by Aluminum Oxide," Appl. Catal., B, 47, 15-25 (2004)

Fujita, H., J. Izumi, M. Sagehashi, T. Fujii and A. Sakoda; "Decomposition of Trichloroethene on Ozone-Adsorbed High Silica Zeolites," Water Res., 38, 166-172 (2004)

Hsing, H.-J., P.-C. Chiang, E.-E. Chang and Y.-S. Li; "Evaluation of Decolorization, Mineralization, and Toxicity Reduction of Tropaeolin O in Water by Ozonation with UV Irradiation," Ozone Sci. Eng., 28, 9-16 (2006)

Kang, J.-W. and M. R. Hoffmann; "Kinetics and Mechanism of the Sonolytic Destruction of Methyl tert-Butyl Ether by Ultrasonic Irradiation in the Presence of Ozone," Environ. Sci. Technol., 32, 3194-3199 (1998)

Sano, N. and D. Yamamoto; "Simulation Model of the Decomposition Process of Phenol in Water by Direct Contact of Gas Corona Discharge in a Cylindrical Reactor," Ind. Eng. Chem. Res., 44, 29822989 (2005)

Sugimitsu, H.; Fundamental and Application of Ozone (Ozone no Kiso to Oyo), pp. 36-41, KORIN Press, Tokyo, Japan (1996)

Yamamoto, T., T. Sugimoto, T. Suzuki, S. R. Mukai and H. Tamon; "Preparation and Characterization of Carbon Cryogel Microspheres," Carbon, 40, 1345-1351 (2002) 